\title{
Fuzzy-Grey Multifactorial Evaluation on the Technological Supporting Ability of the Emergency Management \\ Huang Hongchun ${ }^{1,2}$
}

1. School of Management, Wuhan University of Technology, Wuhan, P.R.China, 430070

2、Guangxi College of Finance and Economic,Guangxi, Nanning, 530030

E-mail: hhch168@163.com

Keywords: Emergency; Emergency Management Technological Supporting Ability; Fuzzy-Grey Multifactorial Evaluation; Index System; Evaluating Model

\begin{abstract}
This paper has set up the evaluation index system of the technological supporting ability of the emergency management and it's evaluating model, used the Fuzzy-Grey multifactorial evaluation to evaluate the technological supporting ability of the emergency management. Thus the useful reference is provided to enhance the building of the technological supporting ability system of the emergency management to improve the comprehensive ability of the emergency management in the future.
\end{abstract}

\section{Introduction}

At present, with the continuous deepening of economic globalization and international cooperation,this put forward the severe challenges to strengthen the construction on the ability of emergency management. because the emergencies occur increasingly frequent, complicated and internationalization, made the losses larger and the influence wider in scope. Therefore, it is extremely important that the government effectively prevent various emergencies happen or reduce the loss caused by all kinds of emergencies to strengthen the construction on the technology support system of emergency management, improve the technological supporting ability of the emergency management with technological innovation and upgrade of the emergency management to push the ascension of the ability of emergency management.

\section{2 research review}

In recent years, as the incident occurred frequently, domestic and international numerous emergency management experts and scholars has produced many research results through keening grasp demand for advanced technology of emergency management,making the technology innovation theory applicate in the field of emergency management, in-depth studying the technological supporting system of the emergencymanagement, strengthening the research and development for the ability of emergency management to further improve the emergency management ability and efficiency. In foreign countries, the United States, Japan, Australia and other major developed countries in many years have deepen the research on the technology innovation of emergency management and the emergency management ability, strengthened the construction on the emergency warning and prevention system,the emergency management information system the emergency management auxiliary decision system,to improve the emergency management ability by using the technology innovation system to push the emergency management technology innovation upgrade ${ }^{[1]}$. Such as 
James LW has put forward for the emergency management ability assessment model in the United States ${ }^{[2]}$; Japanese scholars has analyzed of urban emergency management ability evaluation index ${ }^{[3]}$; Australian academic has researched the emergency ability assessment system include eight contents:policy related to the disaster, disaster preparedness measures, emergency response, disaster mitigation measures, post-disaster assessment, disaster risk assessment, long-term relief and recovery measures and short-term relief measures ${ }^{[4]}$. At home, the research results about the comprehensive evaluation model of the ability of emergency management and the emergency management technology innovation are also more, such as Huang Dianjian has carried on the urban comprehensive evaluation of the ability of emergency management on the basis of the model set statistics theory ${ }^{[5]}$; Zheng Shuangzhong, yun-feng deng has established the weighting method of the city emergency capability assessment index system on the basis of the improved analytic hierarchy process (ahp) ${ }^{[6]}$; Yang qing has established the urban disaster emergency management comprehensive ability evaluation system based on the process management through making the emergency process divide into three parts: before the disaster early warning, the disaster emergency response and the disaster recovery ${ }^{[7]}$; Zhao Ling, NieJinYan has established the urban disaster emergency ability fuzzy comprehensive evaluation model based on fuzzy pattern recognition ${ }^{[8]}$; Professor ying-hua song has put forward the connotation of the technical innovation system of the emergency management ${ }^{[9]}$, in addition,he has proposed the construction on the technology support system in the emergency management ${ }^{[10]}$; Shu-Hua Zhong has proposed the elements of the technology support system in the emergency management ${ }^{[11]}$; Huang Mingxie has proposed the construction goal, main task and policy safeguard measures of the technology support system in the emergency management in hubei province. There is no system research about comprehensive evaluation on the technological supporting ability of the emergency management now. Therefore, this paper, on the basis of the research both at home and abroad, has set up the evaluation index system of the technological supporting ability of the emergency management and it's evaluating model, used the Fuzzy-Grey multifactorial evaluation to evaluate the technological supporting ability of the emergency management. Thus the useful reference is provided to enhance the building of the technological supporting ability system of the emergency management to improve the comprehensive ability of the emergency management in the future.

\section{The Construction on the Evaluation Index System of Technological Supporting Ability of the Emergency Management}

With the extensive exchanges and research by the domestic many emergency management experts and scholars,we has established the evaluation index system of technological supporting ability of the emergency management including four parts: Emergency Prevention and Early Warning Technological Supporting Ability, Emergency Response Technological Supporting Ability,Emergency safeguard Technological supporting ability, Aftermath Restore Technological Supporting Ability. The index of each class has corresponding secondary indicators, there are four primary indicators and 16 secondary indicators, specific content as shown in table 4-1. 


\section{The Model Design of Fuzzy-Grey Multifactorial Evaluation on the Technological Supporting Ability of the Emergency Management}

The factor sets of the evaluation on the technological supporting ability of the emergency management in this paper are shown in table 3-6. W represents the comprehensive value of the evaluation on the technological supporting ability of the emergency management in the target layer. $U$ represents the collection of evaluation index of level 1- $U_{\mathrm{i}}$ in the rule layer. Remember to $U=\left\{U_{1}, U_{2}, U_{3}, U_{m}\right\}$, represents Emergency Prevention and Early Warning Technological Supporting Ability, Emergency Response Technological Supporting Ability,Emergency safeguard Technological supporting ability, Aftermath Restore Technological Supporting Ability. $U_{i}$ represents the collection of evaluation index of level 2- $U_{i j}$ in the index layer.Remember to $U_{i}=\left\{U_{i 1}, U\right.$ $\mathrm{i} 2, . . \mathrm{U}_{\mathrm{ij}}$, among them, $\mathrm{m}=1,2,3,4$ represent four main factors, $\mathrm{J}$ is the factor $\mathrm{j}$ in $\mathrm{i}$ factors of the first class. As shown in table 4-1.

\subsection{Determining the Weights of the Evaluation Index: $U_{i}$ and $U_{i j}$}

In the evaluation index system, the evaluation index $U_{i}$ and $U_{i j}$ has the different importance to the targe $\mathrm{W}$. This paper uses the analytic hierarchy process (AHP) to construct a hierarchical structure model, makes each element belong to the same layer compared one by one according to the "1 9 scaling method, determines the quantitative, establish the judgment matrix,and uses the solving method of matrix eigenvalue to determine the weights the evaluation index: $U_{\mathrm{i}}$ and $\mathrm{U}_{\mathrm{ij}}$. The specific calculation results are as shown in the table 4-1.

the table 4-1: the evaluation index and its weights of the technological supporting ability of the emergency management

\begin{tabular}{|c|c|c|c|c|c|}
\hline \multirow{11}{*}{ 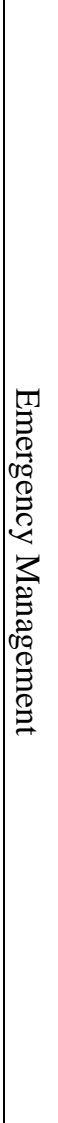 } & \multirow{5}{*}{ 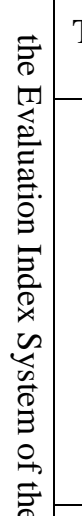 } & The primary evaluationindex & $\begin{array}{l}\text { Weight: } \\
\text { W }\end{array}$ & Thesecondary evaluationindex & Weight: $a_{i j}$ \\
\hline & & \multirow{4}{*}{$\begin{array}{c}\text { Emergency Prevention and Early } \\
\text { Warning Technological } \\
\text { Supporting Ability } U_{1}\end{array}$} & \multirow{4}{*}{0.1296} & $\begin{array}{l}\text { Emergency Prevention Technological } \\
\text { Supporting Ability } U_{11}\end{array}$ & 0.2274 \\
\hline & & & & $\begin{array}{l}\text { Emergency monitoring Technological } \\
\text { Supporting Ability } U_{12}\end{array}$ & 0.2274 \\
\hline & & & & $\begin{array}{l}\text { Risk diagnosis Technological Supporting } \\
\text { Ability } U_{13}\end{array}$ & 0.1221 \\
\hline & & & & $\begin{array}{l}\text { Emergency warning Technological } \\
\text { Supporting Ability } U_{14}\end{array}$ & 0.4232 \\
\hline & \multirow{6}{*}{ 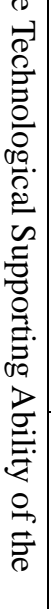 } & \multirow{4}{*}{$\begin{array}{c}\text { Emergency Response } \\
\text { Technological Supporting Ability } \\
U_{2}\end{array}$} & \multirow{4}{*}{0.4824} & $\begin{array}{l}\text { Emergency Decision Technological } \\
\text { Supporting Ability } U_{21}\end{array}$ & 0.2098 \\
\hline & & & & $\begin{array}{l}\text { Emergency Command Auxiliary } \\
\text { Technological Supporting Ability } U_{22}\end{array}$ & 0.2098 \\
\hline & & & & $\begin{array}{l}\text { Emergency Disposal Technological } \\
\text { Supporting Ability } U_{23}\end{array}$ & 0.4644 \\
\hline & & & & $\begin{array}{l}\text { Emergency Coordination Technological } \\
\text { Supporting Ability } U_{24}\end{array}$ & 0.1161 \\
\hline & & \multirow{2}{*}{$\begin{array}{c}\text { Emergency safeguard } \\
\text { Technological supporting ability }\end{array}$} & \multirow{2}{*}{0.2048} & $\begin{array}{l}\text { Resource Integration Technological } \\
\text { Supporting Ability } U_{31}\end{array}$ & 0.4000 \\
\hline & & & & $\begin{array}{l}\text { Iinformation Security Technological } \\
\text { Supporting Ability } U_{32}\end{array}$ & 0.2000 \\
\hline
\end{tabular}




\begin{tabular}{|c|c|c|c|}
\hline \multirow[t]{2}{*}{$U_{3}$} & & $\begin{array}{l}\text { Technical Security Technological } \\
\text { supporting ability } U_{33}\end{array}$ & 0.2000 \\
\hline & & $\begin{array}{l}\text { Mobilization Security Technological } \\
\text { Supporting Ability } U_{34}\end{array}$ & 0.2000 \\
\hline \multirow{4}{*}{$\begin{array}{l}\text { Aftermath Restore Technological } \\
\text { Supporting Ability } U_{4}\end{array}$} & \multirow{4}{*}{0.1833} & $\begin{array}{l}\text { Damage Assessment Technological } \\
\text { Supporting Ability } U_{41}\end{array}$ & 0.1429 \\
\hline & & $\begin{array}{l}\text { Afterward Disposal Technological } \\
\text { Supporting Ability } U_{42}\end{array}$ & 0.2857 \\
\hline & & $\begin{array}{l}\text { Aftermath Social Security Technological } \\
\text { Supporting Ability } U_{43}\end{array}$ & 0.2857 \\
\hline & & $\begin{array}{l}\text { Restoration and Reconstruction } \\
\text { Technological Supporting Ability } U_{44}\end{array}$ & 0.2857 \\
\hline
\end{tabular}

\subsection{Determining the Comment Set and the Sample Matrix}

We devide the evaluation level of of the technological supporting ability of the emergency managementinto four levels in this paper: excellent, good, medium, poor, and set up evaluation sets: $\mathrm{V}=\left\{\mathrm{V}_{1}, \mathrm{~V}_{2}, \mathrm{~V}_{3}, \mathrm{~V}_{4}\right\}$, among them, $\mathrm{V}_{1}, \mathrm{~V}_{2}, \mathrm{~V}_{3}, \mathrm{~V}_{4}$ respectively represent excellent, good, medium, poor, the corresponding level of the emergency management ability respectively represent high, underhigh ,medium, low, and assignment 4,3,2,1 points respectively. index level between two adjacent level, the corresponding score of $3.5,2.5,1.5$.

We invite 8 experts and scholars in the field of emergency management related form a team of expert evaluation, make score for each single index according to the evaluation grade, the score values between 1-4, and fill out the expert assessment, then we fill out the scale sample evaluation matrix $\mathrm{D}$ as follows according to 8 experts assessment

$$
\mathrm{D}=\left(\begin{array}{cccccccc}
2 . & 3 & 2.5 & 2.5 & 3 & 3 & 2.5 & 2 \\
5 & & & & & & & \\
2.5 & 2.5 & 2 & 3 & 2.5 & 2.5 & 3 & 2.5 \\
2 & 2 & 2.5 & 2.5 & 3 & 2.5 & 2 & 2.5 \\
3.5 & 3 & 3 & 3.5 & 3.5 & 3 & 3 & 3 \\
3 & 3 & 3.5 & 3 & 3 & 3 & 3.5 & 3 \\
3 & 3.5 & 3 & 3 & 2.5 & 3 & 3 & 3 \\
4 & 3.5 & 3 & 3 & 4 & 3 & 3.5 & 3 \\
2.5 & 2.5 & 3 & 2.5 & 2.5 & 3 & 2.5 & 2.5 \\
3 & 3 & 3.5 & 3.5 & 3 & 3 & 3 & 3.5 \\
2.5 & 2.5 & 2.5 & 2 & 2.5 & 2.5 & 2 & 2.5 \\
2 & 2 & 2.5 & 2 & 2.5 & 2 & 2.5 & 2.5 \\
2.5 & 2.5 & 3 & 2.5 & 2 & 2.5 & 2 & 2.5 \\
2.5 & 2 & 2.5 & 2.5 & 2.5 & 2 & 2 & 2.5 \\
3 & 3 & 3.5 & 3 & 2.5 & 2.5 & 3 & 3.5 \\
3 & 3 & 3 & 3 & 2.5 & 3 & 2.5 & 3
\end{array}\right)
$$

\subsection{Establishing the Evaluation of Gray Classes and Whitenization Weight Function}

This paper calculates the evaluation index weight matrix by using the gray evaluation 
method. According to the evaluation grade standard of index for Cij, sets up four evaluation class, number of e, the grey class is e $=1,2,3$, 4, respectively represent excellent, good, medium, poor,then make the whitenization weight function according to the qualitative indicators. Four whitenization weight function of the corresponding grey classes is shown in table 4 -2

t he table4-2: whitenization weight function and its schematic diagram

\begin{tabular}{|c|c|c|c|c|}
\hline class & $\begin{array}{l}\text { The grey class } 1 \text { : } \\
\text { “excellent” }\{\mathrm{e}=1\}\end{array}$ & $\begin{array}{l}\text { The grey class 2: } \\
\text { “good” }\{\mathrm{e}=2\}\end{array}$ & $\begin{array}{l}\text { The grey class } 3 \text { : } \\
\text { "medium" }\{\mathrm{e}=3\}\end{array}$ & $\begin{array}{l}\text { The grey class 4: } \\
\text { “poor” }\{\mathrm{e}=4\}\end{array}$ \\
\hline $\begin{array}{c}\text { Grey } \\
\text { number }\end{array}$ & $\begin{array}{l}\text { Grey number } \\
\otimes_{1} \in[0,4,8]\end{array}$ & $\begin{array}{l}\text { Grey number } \\
\otimes_{2} \in[0,3,6]\end{array}$ & $\begin{array}{l}\text { Grey number } \\
\otimes_{3} \in[0,2,4]\end{array}$ & $\begin{array}{c}\text { Grey number } \\
\otimes_{4} \in[0,1,2]\end{array}$ \\
\hline 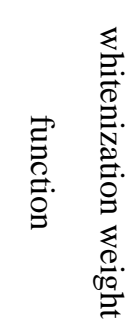 & $\begin{array}{l}f_{1}\left(d_{i j k}^{(s)}\right) \\
= \begin{cases}d_{i j k}^{(s)} / 4 & d_{i j k}^{(s)} \in[0,4] \\
1 & d_{i j k}^{(s)} \in[4,8] \\
0 & d_{i j k}^{(s)} \notin[0,8]\end{cases} \end{array}$ & $\begin{array}{l}f_{2}\left(d_{i j k}^{(s)}\right) \\
=\left\{\begin{array}{cc}d_{i j k}^{(s)} / 3 & d_{i j k}^{(s)} \in[0,3] \\
-\left(6-d_{i j k}^{(s)}\right) / 3 & d_{i j k}^{(s)} \in[3,6] \\
0 & d_{i j k}^{(s)} \notin[0,6]\end{array}\right.\end{array}$ & $\begin{array}{l}f_{3}\left(d_{i j k}^{(s)}\right) \\
\left\{\begin{array}{cc}d_{i j k}^{(s)} / 2 & d_{i j k}^{(s)} \in[0,2] \\
\left(4-d_{i j k}^{(s)}\right) / 2 & d_{i j k}^{(s)} \in[2,4] \\
0 & d_{i j k}^{(s)} \notin[0,4]\end{array}\right.\end{array}$ & $\begin{array}{l}f_{4}\left(d_{i j k}^{(s)}\right) \\
=\left\{\begin{array}{cc}1 & d_{i j k}^{(s)} \in[0,1] \\
\left.2-d_{i j k}^{(s)}\right) / 1 & d_{i j k}^{(s)} \in[1,2] \\
0 & d_{i j k}^{(s)} \notin[0,2]\end{array}\right.\end{array}$ \\
\hline 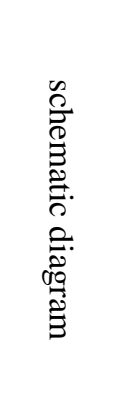 & $\underset{4}{\stackrel{i}{\longrightarrow}} d_{i j k}^{(s)}$ & $\sum_{0}^{(s)}$ & $\begin{array}{r}f_{3} \\
1 \\
1\end{array}$ & $\begin{array}{c}0 \\
d_{i j k}^{(s)}\end{array}$ \\
\hline
\end{tabular}

\subsection{Calculating Grey Evaluation Coefficient}

To The evaluation index of $\mathrm{U}_{\mathrm{ij}}$, the grey evaluation coefficient of the index $\mathrm{S}$ belonging to the evaluation grey class e is for $x_{i j e}^{(s)}$, there are: $x_{i j t}^{(s)}=\sum_{k=1}^{p} f_{e}\left(d_{i j e}^{(s)}\right)$

To The evaluation index of $U_{\mathrm{ij}}$, the total grey evaluation coefficient of the index $\mathrm{S}$ belonging to the each evaluation grey class is for $x_{i j}^{(s)}$, there are: $x_{i j t}^{(s)}=\sum_{e=1}^{4} f_{e}\left(d_{i j e}^{(s)}\right)$

To The evaluation index of $U_{11}$, the count of each grey class are as follows: $\mathrm{e}=1$

$x_{111}=f_{1}(2.5)+f_{1}(3)+f_{1}(2.5)+f_{1}(2.5)+f_{1}(3)+f_{1}(3)+f_{1}(2.5)+f_{1}(2)$

$=2.5 / 4+3 / 4+2.5 / 4+2.5 / 4+3 / 4+3 / 4+2.5 / 4+2 / 4=5.25$

$\mathrm{e}=2$

$x_{112}=f_{2}(2.5)+f_{2}(3)+f_{2}(2.5)+f_{2}(2.5)+f_{2}(3)+f_{2}(3)+f_{2}(2.5)+f_{2}(2)$

$=2.5 / 3+1+2.5 / 3+2.5 / 3+1+1+2.5 / 3+2 / 3=7$ 


$$
\begin{aligned}
& \mathrm{e}=3 \\
& x_{113}=f_{3}(2.5)+f_{3}(3)+f_{3}(2.5)+f_{3}(2.5)+f_{3}(3)+f_{3}(3)+f_{3}(2.5)+f_{3}(2) \\
& =1.5 / 2+1 / 2+1.5 / 2+1.5 / 2+1 / 2+1 / 2+1.5 / 2+1=5.5 \\
& \mathrm{e}=4 \\
& x_{114}=f_{4}(2.5)+f_{4}(3)+f_{4}(2.5)+f_{4}(2.5)+f_{4}(3)+f_{4}(3)+f_{4}(2.5)+f_{4}(2) \\
& =0+0+0+0+0+0+0+0=0 \\
& \text { So the total evaluation coefficient of } U \text { 11 for: } \\
& X_{11}=X_{111}+X_{112}+X_{113}+X_{114}=5.25+7+5.5+0=17.75
\end{aligned}
$$

Similarly, the grey evaluation coefficien of other index can be calculated by the same methom.

\subsection{Calculating Grey Evaluation Weight Vector and Weight MatrX}

The evaluation weight vector of the index $\mathrm{U}_{11}$ is for $r_{11}$

$$
r_{11}=\left(x_{111} / x_{11}, x_{112} / x_{11}, x_{113} / x_{11}, x_{114} / x_{11}\right)=(0.296,0.394,0.310,0)
$$

Similarly, the evaluation weight vector of 15 indexes such as $r_{12}, r_{13}, r_{14}, \ldots, r_{44}$ be calculated by the same methom.

According to the above calculation, we get that the grey fuzzy evaluation matrix of the index such as $U_{1} 、 U_{2} 、 U_{3}, U_{4}$ respectively is for $R_{1}, R_{2}, R_{3} 、 R_{4}$.

$$
\begin{aligned}
& R_{1}=\left[\begin{array}{l}
r_{11} \\
r_{12} \\
r_{13} \\
r_{14}
\end{array}\right]=\left[\begin{array}{llll}
0.296 & 0.394 & 0.310 & 0.00 \\
0.289 & 0.386 & 0.325 & 0.00 \\
0.270 & 0.360 & 0.370 & 0.00 \\
0.372 & 0.438 & 0.190 & 0.00
\end{array}\right] \quad R_{2}=\left[\begin{array}{l}
r_{21} \\
r_{22} \\
r_{23} \\
r_{24}
\end{array}\right]=\left[\begin{array}{llll}
0.359 & 0.440 & 0.201 & 0.00 \\
0.340 & 0.434 & 0.226 & 0.00 \\
0.415 & 0.431 & 0.154 & 0.00 \\
0.296 & 0.394 & 0.310 & 0.00
\end{array}\right] . \\
& R_{3}=\left[\begin{array}{l}
r_{31} \\
r_{32} \\
r_{33} \\
r_{34}
\end{array}\right]=\left[\begin{array}{llll}
0.386 & 0.436 & 0.178 & 0.00 \\
0.270 & 0.360 & 0.370 & 0.00 \\
0.257 & 0.343 & 0.400 & 0.00 \\
0.277 & 0.369 & 0.355 & 0.00
\end{array}\right] \quad R_{4}=\left[\begin{array}{l}
r_{41} \\
r_{42} \\
r_{43} \\
r_{44}
\end{array}\right]=\left[\begin{array}{llll}
0.264 & 0.352 & 0.385 & 0.00 \\
0.346 & 0.423 & 0.231 & 0.00 \\
0.321 & 0.428 & 0.251 & 0.00 \\
0.386 & 0.436 & 0.178 & 0.00
\end{array}\right] .
\end{aligned}
$$

\subsection{Calculating Comprehensive Evaluation Value}

4.6.1 Evaluating the value of the primary evaluation index $U_{1}$. The evaluation of the primary evaluation index $\mathrm{U}_{1}$ is for $\mathrm{B}_{1}$ :

$$
\mathrm{B}_{1}=\mathrm{W}_{1} \cdot \mathrm{R}_{1}=(0.3234,0.4068,0.2700,0)
$$

Similarly, we can calculate that the comprehensive evaluation value of the index such as $\mathrm{U}_{2} 、 \mathrm{U}_{3}, \mathrm{U}_{4}$ is for $\mathrm{B}_{2}, \mathrm{~B}_{3}, \mathrm{~B}_{4}$ 


$$
R=\left[\begin{array}{l}
B_{1} \\
B_{2} \\
B_{3} \\
B_{4}
\end{array}\right]=\left[\begin{array}{llll}
0.3234 & 0.4068 & 0.2700 & 0.00 \\
0.3738 & 0.4293 & 0.1971 & 0.00 \\
0.3152 & 0.3888 & 0.2962 & 0.00 \\
0.3386 & 0.4151 & 0.2436 & 0.00
\end{array}\right]
$$

4.6.2 Calculating the comprehensive evaluation value. According toR $=\left(\mathrm{B}_{1}, \quad \mathrm{~B}_{2}, \mathrm{~B}_{3}\right.$, $\left.\mathrm{B}_{4}\right)^{\mathrm{T}}$, and $\mathrm{W}=(0.1296,0.4824,0.2048,0.1833)$, we can calculate that the comprehensive evaluation value $\mathrm{B}$ is for: $\mathrm{B}=\mathrm{W} * \mathrm{R}=(0.3489,0.4155,0.2355,0)$, we set that the assignment of each evaluation grey class is give by the "grey level", the grey class 1:“excellent”is for 4, The grey class 2:"good” for 3, The grey class 3:“medium”is for 2, The grey class 4: "poor"is for 1,then we get the grey evaluation weight vector At all levels $\mathrm{C}$ is for $\mathrm{C}=(4,3,2,1)$, so the comprehensive evaluation value of the technological supporting ability of the emergency management is as follows:

$$
\mathrm{U}=\mathrm{B} * \mathrm{C}^{\mathrm{T}}=(0.3489,0.4155,0.2355,0) *(4,3,2,1)^{\mathrm{T}}=3.1131
$$

\section{5 the evaluation results analysis}

We , based on the above analysis on the fuzzy grey comprehensive evaluation method, can get the fuzzy grey comprehensive evaluation value of 3.1131 in the technological supporting ability of the emergency management. According to the evaluation criteria ,the technological supporting ability of the emergency management belongs to the good level, but according to the senior level,it is still some distance.

Based on the weight of the primary index and the secondary index by determined the AHP method, we know that, in the primary index ,the proportion of Emergency Response Technological Supporting Ability and Emergency safeguard Technological Supporting Ability is large, accounted for 48.24\%, 20.48\% respectively; the proportion of Aftermath Restore Technological Supporting Ability and Emergency Prevention and Early Warning Technological Supporting Ability is relatively small, accounted for $18.33 \%$, $12.96 \%$ respectively. In secondary index, the index hasing large proportion are Emergency warning Technological Supporting Ability, Emergency Disposal Technological Supporting Ability, Resource Integration Technological Supporting Ability, Afterward Disposal Technological Supporting Ability, Restoration and Reconstruction Technological Supporting Ability,but the index hasing small proportion are Risk diagnosis Technological Supporting Ability, Emergency Coordination Technological Supporting Ability, Damage Assessment Technological Supporting Ability. This shows that,in the system of the technological supporting ability of the emergency management,the primary index of Emergency Response Technological Supporting Ability and Emergency safeguard Technological Supporting Ability has a large weight,we should strengthen the construction of these two aspects; the secondary index of Emergency warning Technological Supporting Ability, Emergency Disposal Technological Supporting Ability, Resource Integration Technological Supporting Ability, Afterward Disposal Technological Supporting Ability, Restoration and Reconstruction Technological Supporting Ability also has a large weight, should strengthen the construction on them. 


\section{6 conclusion}

This paper, based on the system of the technological supporting ability of the emergency management as the evaluation object and the comprehensive emergency management as a guide,constructs the evaluation index system, sets up the evaluation model, makes the comprehensive evaluation by using fuzzy grey comprehensive evaluation method to improve the system of the technological supporting ability of the emergency management. Evaluation results show that using fuzzy grey comprehensive evaluation method to evaluate the technological supporting ability of the emergency management has the scientific nature and feasibility, to provide the reference basis to strengthen the construction on the technological supporting ability of the emergency management

\section{References}

[1] Song Yinghua. Introduction to Public Emergency Management. China's economy Press, 2009, 16-18(in Chinese)

[2] James LW.A report to the unite states senate committee on appropriations: state capabiliyy assessment for readiness.Federal Emergency,1997,6(12):122-125

[3] Deng Yunfeng, Zheng Shuangzhong, liu tie-min. Sudden Disaster Emergency Ability Assessment and Emergency Characteristics [J]. Journal of safety science and technology of China,2005, 1(5):56-58 (in Chinese)

[4] Department of Transport \& Regional Serviees.2002.Natural Disasters in Australia:Reforming mitigation, relief \& reeovery arrangements--A report to the Council of Australian Governments by a high level official's group.(2002--08).http://www.ema.gov.au/

[5] wu Zongzhi, Huang Dianjian. The Evaluation Method Research on Urban Emergency Shelter Emergency Ability based on the Theory of Fuzzy Set Value[J]. Journal of safety and the environment, 2005(12):100-103(in Chinese)

[6]Zheng Shuangzhong,Deng yunfeng, Tien han jiang. The Core Processing Method Research on the City Emergency Ability Assessment Index System[J]. Journal of safety science and technology of China,2006,10:20-23(in Chinese)

[7]Yang qing, Song ying hua. The Evaluation System Research on the Comprehensive Ability of Urban Disaster Emergency Management based on Process Management [J]. China's administrative management.2007,3:103-106(in Chinese)

[8] Zhao Ling, NieJinYan. The Application of Fuzzy Pattern Recognition Model in Urban Disaster Emergency Capability Evaluation [J]. China's public security.2008,13(9):2-3

[9] Song.Yinghua. The Construction Research on Technology Innovation System of Emergency Management [J]. Journal of management science and technology. 2009. (04): 87-90

[10] Song Yinghua. The Research Report on the Construction to the Technology Support System of Emergency management in hubei province [R]. 2008.10: 24-26

[11] Zhong Shuhua. The Framework Idea of National Emergency Technology Support System [J]. Science and technology of China, 2004. (05): 32-35 